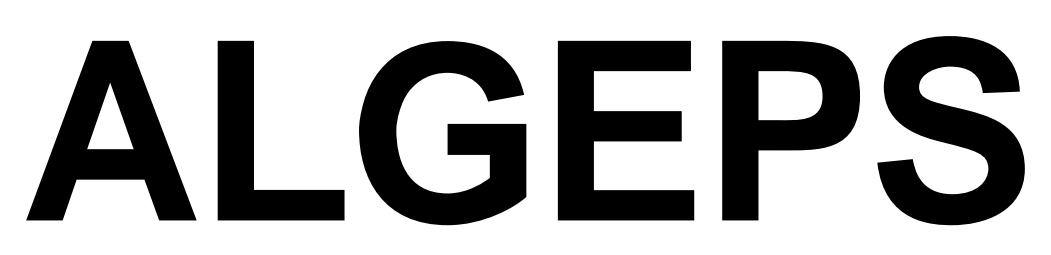

REVISTA DE GEOLOGIA, SÈRIE B no 589 - Maig del 2012 


\section{RECORRIDO DESDE BOLTAÑA A FISCAL, A BROTO Y A TORLA, A TRAVÉS DEL PATRIMONIO GEOLÓGICO Y MINERO DE LA COMARCA DEL SOBRARBE}

\section{ADVERTENCIAS PREVIAS}

Como en otros recorridos de RECONOCIMIENTO GEOLÓGICO (o de RECONOCIMIENTO GEOLÓGICO Y MINERO), el recorrido se compondrá de diversas PARADAS.

Por otra parte, habrá que tener en cuenta, en todo momento, (especialmente antes de empezar los recorridos de los diferentes tramos), el estado de los caminos y carreteras, por donde transitará el recorrido. Como es el caso del camino de acceso a Bujaruelo, entre otros.

Finalmente, como ya hacemos en otros recorridos similares, queremos decir que hace falta tener un cuidado muy especial en el respeto a la naturaleza, a lo largo de todo el recorrido del itinerario, y también fuera de él.

\section{BREVE INTRODUCCIÓN GEOLÓGICA}

Todo el recorrido de este itinerario, se desarrollará por distintas zonas ocupadas por el Sistema Pirenaico (o simplemente por los Pirineos). Concretamente, en todo el recorrido se circulará por el denominado Surpirineo Central.

Así, el recorrido se iniciará en las cercanías de Boltaña, dentro del denominado Surpirineo Central, por los denominados Pirineos Meridionales (también a menudo conocidos como Prepirineo Meridional).

Así, se irá circulando desde Boltaña hasta Torla, en el Valle de Ordesa, penetrando así en el Manto de Gavarnie.

\section{BREVE INTRODUCCIÓN GEOGRÁFICA}

El recorrido del presente itinerario se efectuará exclusivamente por una comarca aragonesa, por la del Sobrarbe. Así el recorrido se iniciará en la capital comarcal, en Boltaña, para ir luego hacía las localidades de Fiscal, Broto y Torla, en cuyo término municipal finalizará. 
Por otro lado, la totalidad del recorrido transitará dentro de la cuenca del río Ara, desde Boltaña hasta casi su nacimiento en el Valle de Bujaruelo. Este río, aguas debajo de Boltaña vierte sus aguas al Cinca, en l'Ainsa, concretamente, la otra capital comarcal del Sobrarbe.

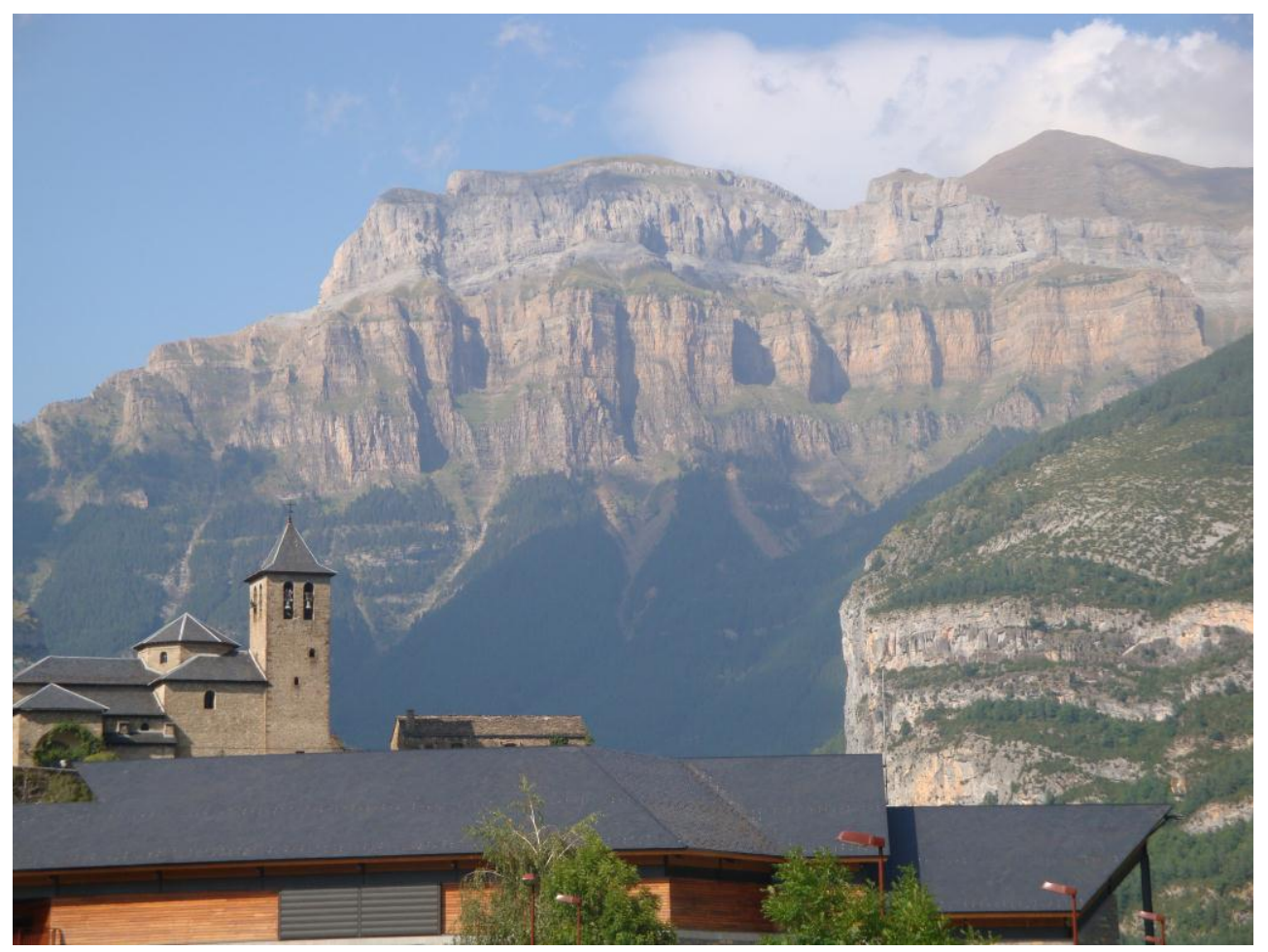

Torla, ante el Valle de Ordesa

\section{OBJETIVOS GENERALES DE ESTE ITINERARIO}

En este itinerario, los objetivos generales que se han de conseguir, se pueden concretar en los siguientes aspectos:

1.- Estudio y reconocimiento de los materiales mesozoicos y cenozoicos situados en el Surpirineo Central. Estos materiales los iremos encontrando a lo largo de todo el recorrido del itinerario.

2.- Estudio y reconocimiento de las estructuras del Surpirineo Central, a lo largo de todo el recorrido del itinerario. En los tramos finales, realizaremos la observación y estudio del Manto de Gavarnie.

3.- Visión de algunas de las antiguas explotaciones encontradas a lo largo del recorrido del itinerario.

4.- Visión de los diferentes lugares directamente relacionados con el Patrimonio Geológico que iremos encontrando a lo largo del recorrido de este itinerario. Dentro de este, cabe considerar todo el relacionado con el Valle de Ordesa. 
5.- Visión de los diferentes lugares directamente relacionados con el Patrimonio Minero que veremos a lo largo del recorrido de este itinerario.

\section{ANTECEDENTES BIBLIOGRÁFICOS}

En relación con este itinerario, no conocemos ningún antecedente, de otro autor relativo a otro itinerario que discurra por este lugar. Así pues, en este sentido va a ser una primicia en todos los aspectos.

Por otra parte, haremos mención de algunos trabajos, de carácter geológico generalista, que corresponden a los trabajos del IGME (1972, 1974 y 1975), relativos al Mapa Geológico de España (a Escala 1.200.000), al Mapa Metalogenético de España y al Mapa de Rocas Industriales de España.

Con respecto a las mineralizaciones que iremos encontrando, mencionaremos los trabajos de: CALVO et altri (1988); MAESTRE (1845); así como nuestros trabajos: MATA-PERELLÓ (1987 y 1992).

También mencionaremos el trabajo de PRAMES (2005) dedicado a la comarca del Sobrarbe. Así como el del GOBIERNO DE ARAGÓN (2001), dedicado a los Puntos de Interés Geológico de Aragón.

Finalmente, diremos que todos estos trabajos (así como otros que ahora no hemos aludido), figurarán mencionados, por orden alfabético, en el apartado dedicado a las REFERENCIAS BIBLIOGRÁFICAS.

\section{RECORRIDO DEL ITINERARIO}

Este recorrido se iniciará en las inmediaciones de la población de Boltaña, por donde se efectuará la primera parada del itinerario. Tras ello, el recorrido se encaminará hacía Broto por la carretera N-260. Así, pronto se llegará a Jánovas. En este tramo se efectuará una nueva parada.

Luego, el recorrido se dirigirá hacía la población de Lavelilla y Lacort, llegándose luego a Fiscal. Tras ello, el recorrido se dirigirá hacía el Norte, pasando por las inmediaciones de Asin de Broto y luego por Sarvisé, en donde se realizará una nueva parada.

Tras ello, el recorrido continuará hacía Broto, en donde se hará una nueva parada en la Cascada de Sorrosal. Después el recorrido seguirá hacía el Norte, realizando una hijuela hacía Linás de Broto y hacía el Túnel de Cotefablo.

Tras terminar esta hijuela, cabrá volver atrás para continuar hacía el Norte, yendo a Torla, realizándose las últimas paradas en los valles de Bujaruelo y de Ordesa, ya dentro del Parque Nacional de Ordesa. 


\section{DESCRIPCIÓN DEL ITINERARIO}

Como de costumbre, haremos una serio de PARADAS (o ESTACIONES), en donde se realizaran diversas explicaciones en torno a las características del lugar en donde se halla la PARADA.

Por otra parte, en ellas haremos mención del término municipal dónde se encuentran, así como del número del "Mapa Topográfico Nacional (a escala 1:50.000, que indicaremos entre paréntesis. Así, ahora (en este recorrido) utilizaremos solamente las hojas: 146 (o de Bujaruelo), 177 (o de Biescas), 178 (o de Broto) y 211 (o de Boltaña).

Así, la relación ordenada de las paradas que constituyen el recorrido de este itinerario, es la siguiente:

PARADA 1. CASTILLO DE BOLTAÑA, (término municipal de Boltaña, comarca del Sobrarbe). (Hoja 211).

El recorrido del presente itinerario, cabe iniciarlo en las cercanías de Boltaña, concretamente en el camino que conduce hasta las ruinas del Castillo, a menos de $1 \mathrm{Km}$ de la población.

Tanto el recorrido como el lugar en donde ahora estamos, se encuentra situado dentro del Sistema Pirenaico; y más concretamente en los Pirineos Meridionales, concretamente en el Surpirineo Central, entre afloramientos de los materiales mesozoicos del Cretácico.

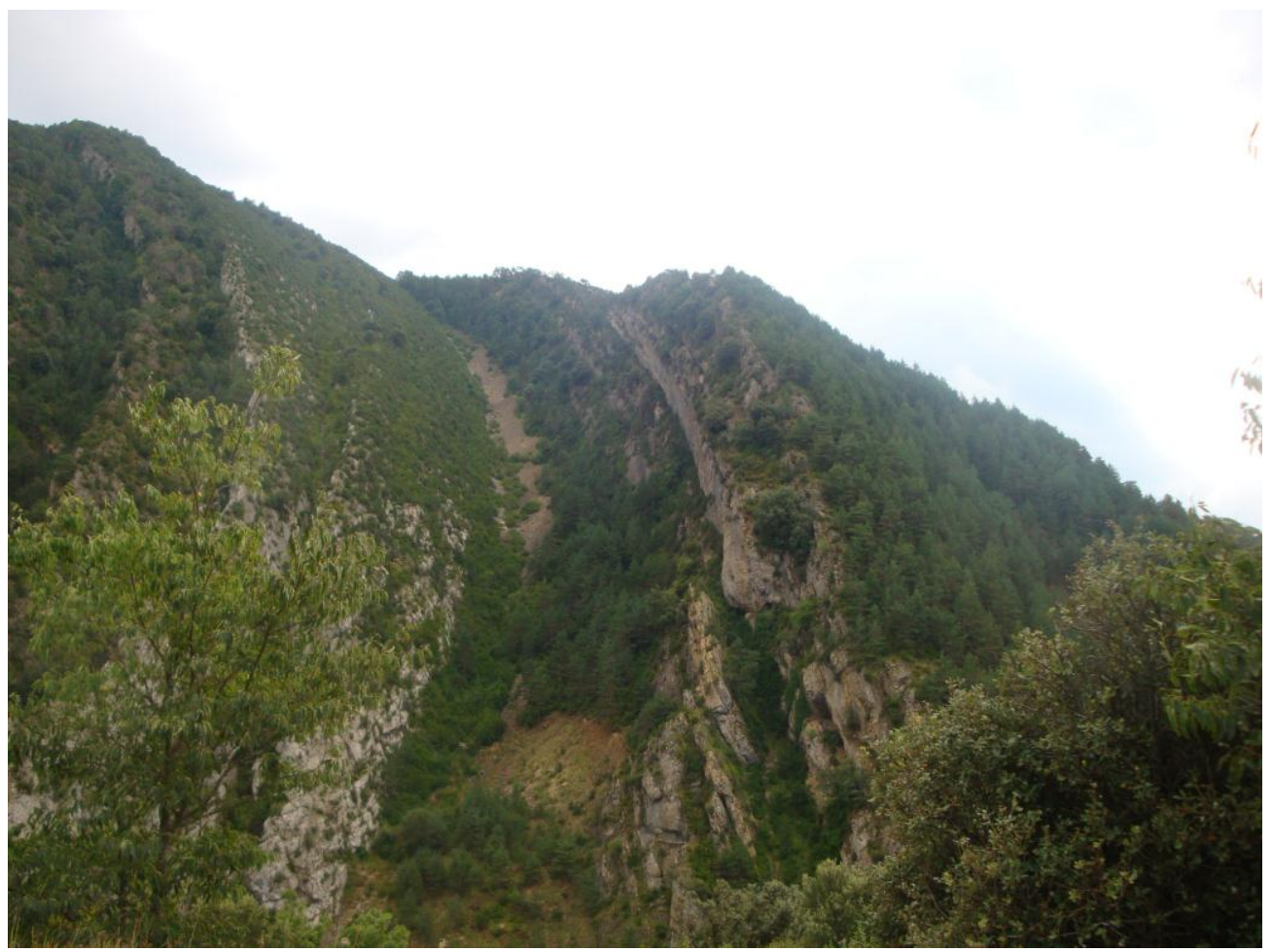

Anticlinal de Boltaña, flanco oriental 
Desde este lugar, mirando hacía el ONO (hacía Ferreras), puede verse el Anticlinal de Boltaña (más concretamente su flanco oriental). Este anticlinal está conformado por afloramientos de los materiales mesozoicos del Cretácico. Cabe decir que en las cercanías de los restos del Castillo, en donde estamos, hay un plafón indicativo de este interesante anticlinal.

PARADA 2. MIRADOR DE JÁNOVAS, (Jánovas, término municipal de Fiscal comarca del Sobrarbe). (Hoja 211).

Después de realizar la parada anterior, cabe retornar a Boltaña, para bajar hasta la carretera N-260, con la intención de continuar por ella hacía el Oeste. Así, pronto encontraremos el cruce con la carretera que conduce al Puerto de Sarablo (por la izquierda). Más adelante llegaremos al Mirador de Jánovas, en donde haremos una nueva parada, después de recorrer unos 8’5 Km desde la anterior.

En este recorrido habremos transitado siempre junto al río Ara, encontrando afloramientos de los materiales mesozoicos del borde oriental del Anticlinal de Boltaña. Estos materiales mesozoicos del Cretácico, forman parte del Pirineo Meridional, que ya hemos citado anteriormente. Entre estos materiales, el río Ara pasa formando un desfiladero.

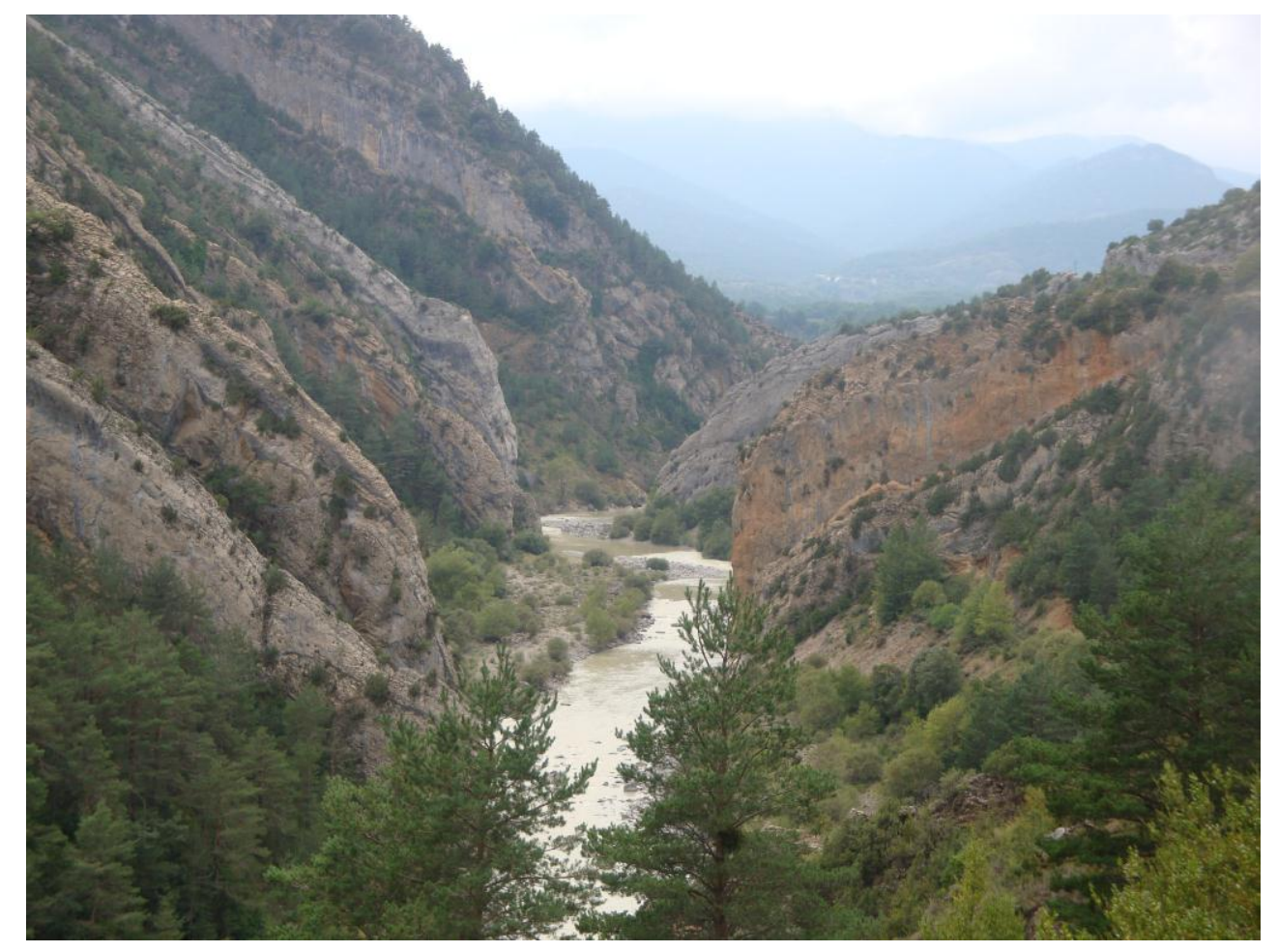

Desfiladero del Ara entre Boltaña y Jánovas

Flanco oriental del Anticlinal De Boltaña

Luego al llegar al Mirador de Jánovas, aparece aguas arriba del mismo una interesante planicie que se extiende hasta Fiscal. Se trata de una antigua laguna de origen 
glaciar, rellena por los sedimentos del río Ara. Esta planicie se hace más extensa por los alrededores de los pueblecitos de Albella y de Lacort.

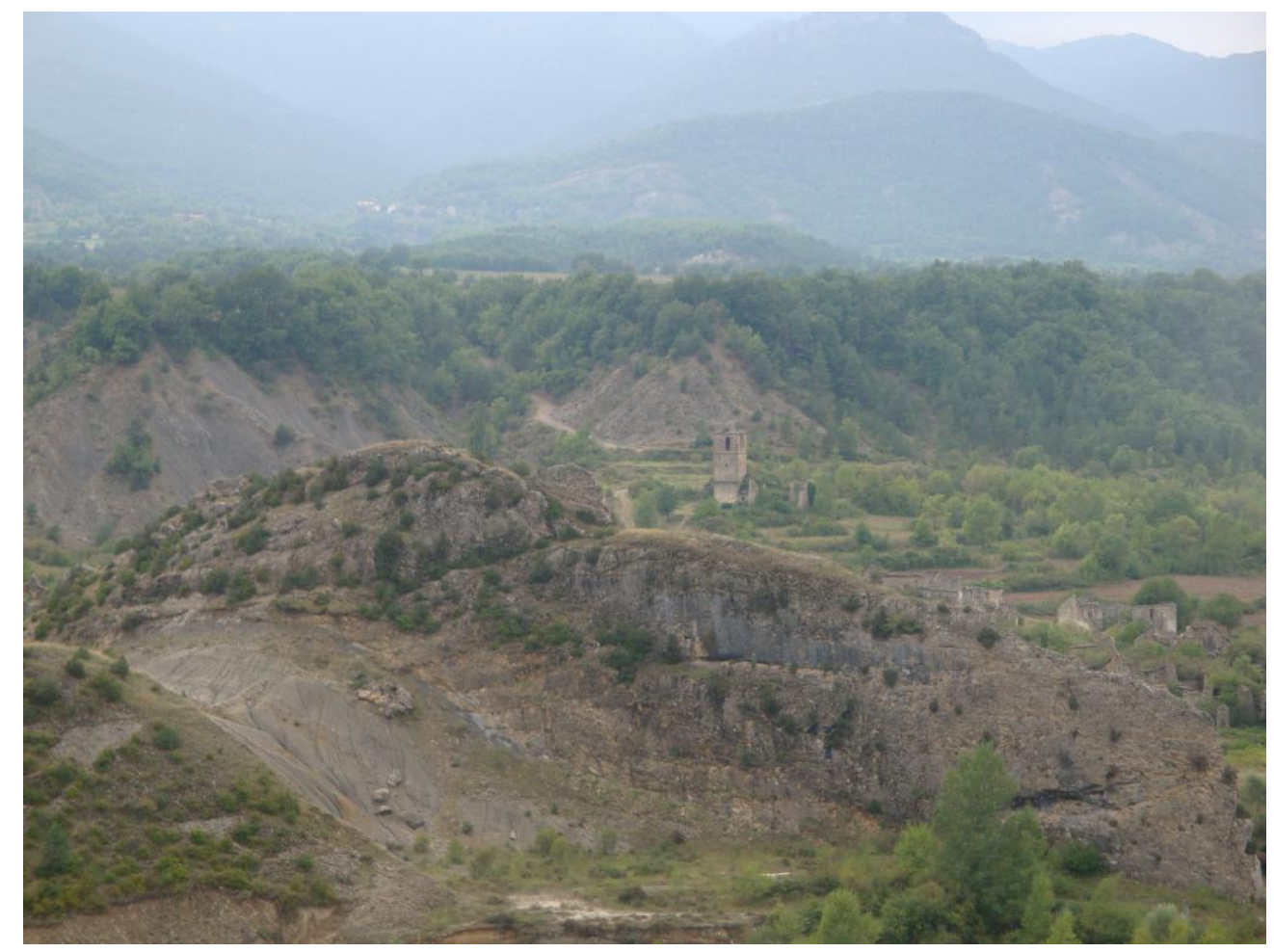

Jánovas (con el campanario a la derecha de la fotografía) y la parte meridional del llano.

\section{PARADA 3. BARRANCO DE CHALÉ, (Sarvisé, término municipal de Broto, comarca del Sobrarbe). (Hoja 178).}

Desde la parada anterior, es necesario continuar por la carretera que conduce hacía Broto (la N-260). Por esta carretera, tras dejar a la izquierda el cruce de Jánovas, se pasará por las inmediaciones de Lavelilla y Lacort, situados a la derecha de la carretera. Luego, se dejara el ramal que conduce a Ligüerri de Ara (por la izquierda de la carretera). Más adelante se dejará Arresa a la derecha, llegando a Fiscal (de donde partirá la carretera a Sabiñánigo. Ahora en construcción, en 2009). Más adelante, tras dejar Asín de Broto a la derecha, se llegará a Sarvisé. Sin embargo, a menos de $1 \mathrm{Km}$ de este pueblo, puede efectuarse una nueva parada junto al Barranco de Chalé. Así, desde la anterior se habrán recorrido unos $20 \mathrm{Km}$.

Buena parte de este recorrido, lo habremos efectuado por la planicie que hemos mencionado en la parada anterior, concretamente entre las inmediaciones de Jánovas (al principio del recorrido) y Fiscal. Luego, el río Ara, junto al cual hemos realizado este recorrido, se encaja ligeramente entre la última localidad mencionada y las inmediaciones de Asín de Broto. A partir de este momento, se habrá vuelto a ensanchar el valle del río Ara, ya que habremos entrado en otra planicie, la de Planduvial, frente a la cual nos encontramos ahora situados. Esta se extiende hasta más allá de Broto. 
Como en el caso anterior, se trata de una antigua laguna de origen glaciar, colmatada por los materiales detríticos aportados por el río Ara y sus afluentes.

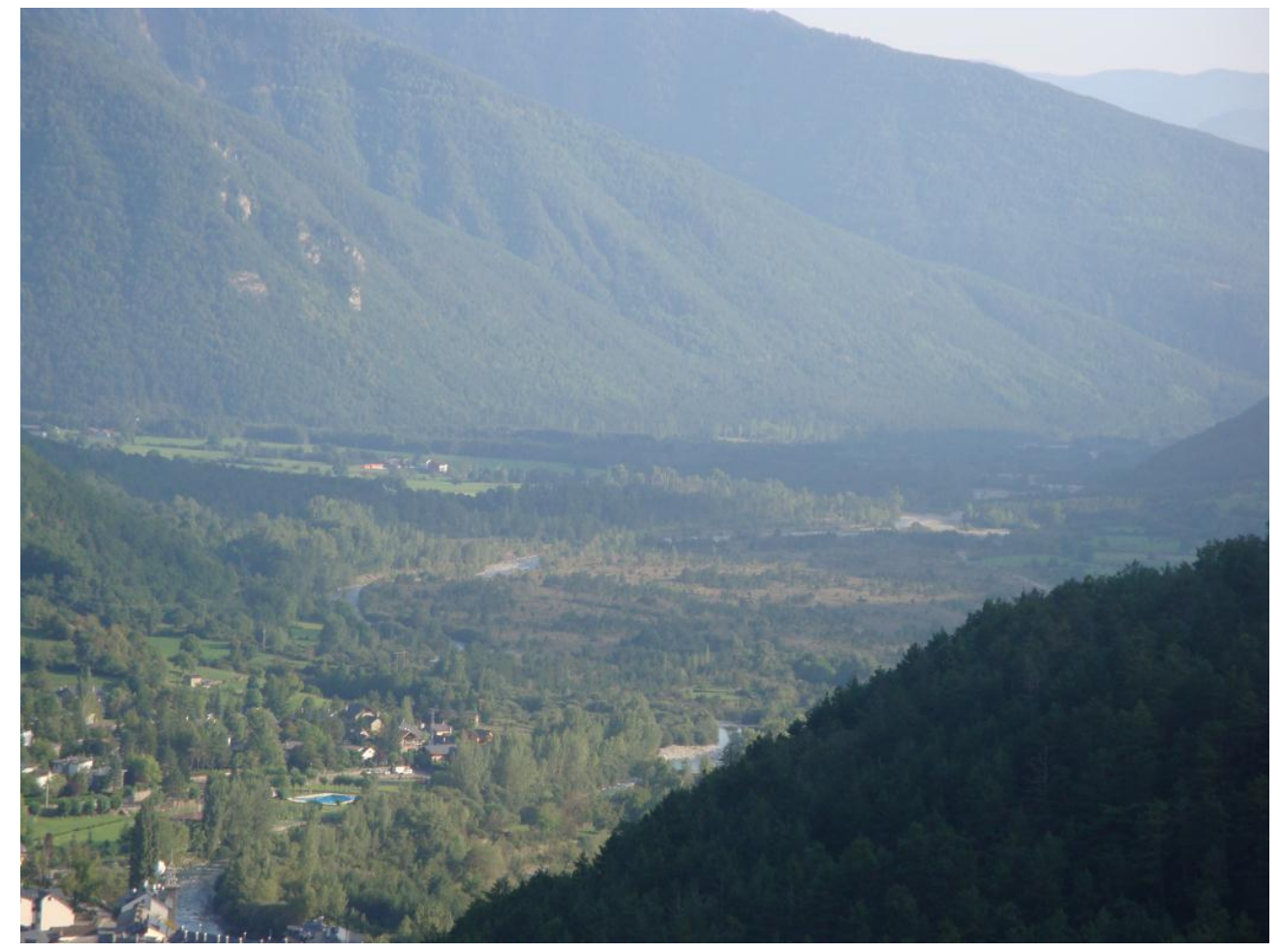

Un aspecto de la laguna colmatada.

Por otra parte, la totalidad de este recorrido la habremos realizado dentro de los Pirineos Meridionales, en donde estamos situados desde el inicio del recorrido de este itinerario.

PARADA 4. CASCADA DE SORROSAL, (término municipal de Broto, comarca del Sobrarbe). (Hoja 178).

Tras realizar la parada anterior, conviene retornar a la carretera para continuar hacía el norte, siguiendo siempre por la carretera nacional N-260. Así, tras dejar Sarvisé (de donde sale por la derecha el ramal carreteril que conduce a Fanlo), llegaremos pronto a Broto. Desde ahí nos convendrá pasar a la otra parte del río Ara, con la intención de llegar al paraje de la Cascada de Sorrosal, ahí (al pie de la misma) efectuaremos una nueva parada, habiendo recorrido unos $4,5 \mathrm{Km}$, aproximadamente.

Como en el caso anterior, la totalidad de este recorrido la habremos efectuado junto al río Ara (que finalmente, en Broto, hemos cruzado). Por otra parte, hemos estado recorriendo la planicie de Planduvial, a la que nos hemos referido en la parada anterior. Precisamente ahora hemos salido de ella.

Por otra parte, la totalidad del recorrido se habrá efectuado entre afloramientos de los materiales cenozoicos y mesozoicos que forman parte de los Pirineos Meridionales, en donde nos encontramos desde el principio del recorrido en Boltaña. 
En este lugar, nos encontramos frente a una interesante cascada. Ésta está formada por el río Sorrosal, al llegar al cauce del Ara. En efecto, el río Sorrosal transcurre por el valle glacial de Linás de Broto, cuyo nivel de base es más alto que el de Broto, por donde discurre el río Ara. Se trata de una morfología normal entre los valles glaciares, en donde los valles tributarios tienen un nivel de base más alto que el de los valles principales, como sucede en este caso.

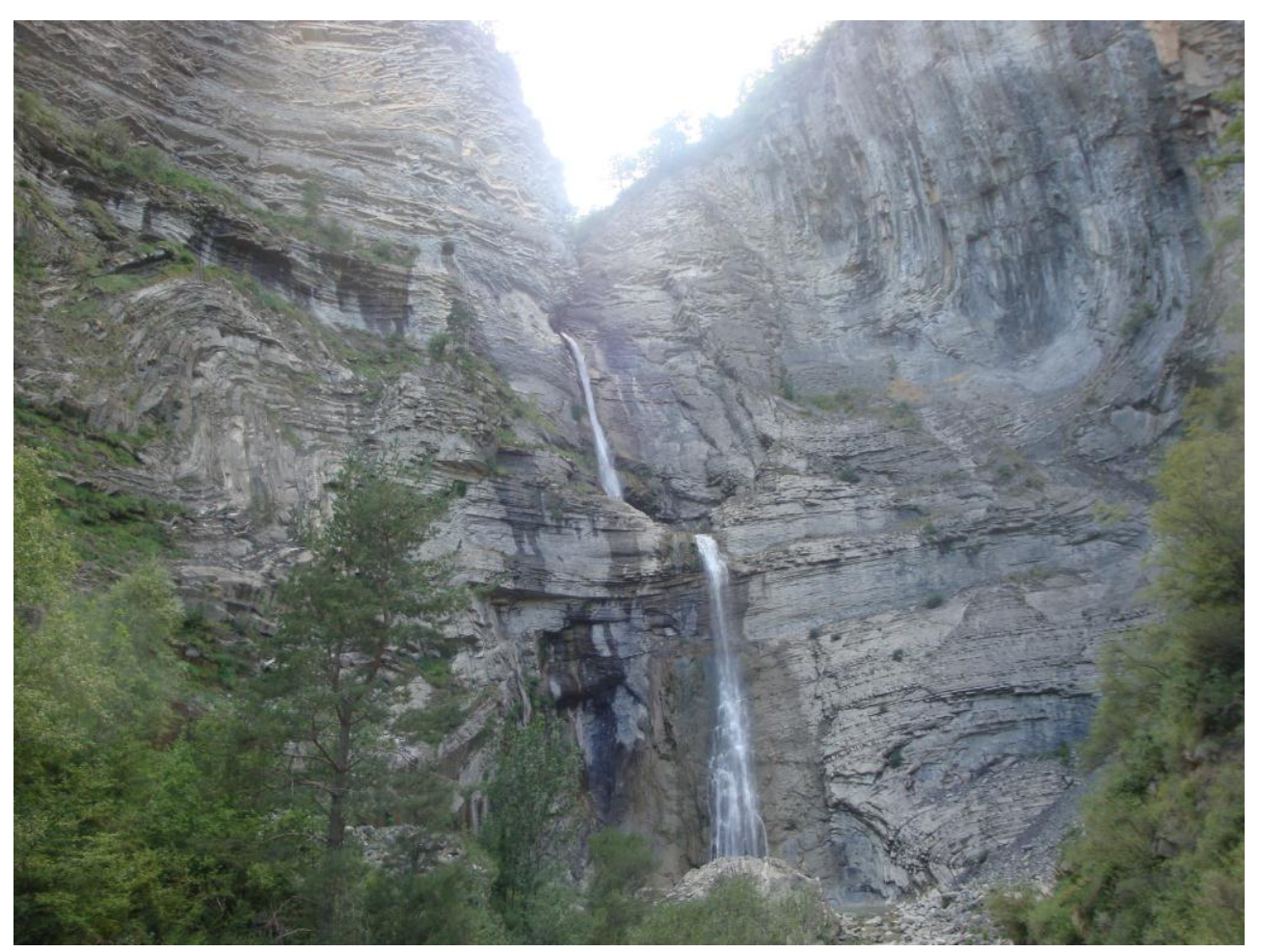

Un aspecto frontal de la cascada

\section{PARADA 5 - CONDICIONAL. PUERTO DE COTEFABLO, (término municipal de Linás de Broto, comarca del Sobrarbe). (Hoja 178).}

Tras efectuar la parada anterior, cabe regresar de nuevo al pueblo de Broto. Ahí, de nuevo en la carretera N-260, será necesario continuar por ella hacía el Norte. A los 3 Km se encontrará el cruce de Torla (donde iremos después). Sin embargo, podemos efectuar una hijuela, continuando por la carretera N-260 hacía el Puerto de Cotefablo. En este recorrido, tras el cruce, iremos encontrando las poblaciones de Frajen y Viu. Luego llegaremos a Linás de Broto, continuando hacía la entrada del Túnel del Puerto de Cotefablo. Ahí efectuaremos una nueva parada, tras haber recorrido unos $12 \mathrm{Km}$, desde la parada anterior.

En principio, habremos efectuado el recorrido junto al río Ara. Sin embargo, tras el cruce habremos entrado en el valle del río Sorrosal (tributario del Ara, en Broto). Como ya hemos comentado en la parada anterior, este rió discurre por un valle glaciar, situada a más altura que la del valle principal, por donde transcurre el río Ara. Como hemos visto anteriormente, el desnivel entre los dos valle, el río Sorrosal, lo soluciona mediante una cascada. 
Por otra parte, en este recorrido habremos ido encontrando afloramientos de los materiales mesozoicos y cenozoicos que forman parte del Pirineo Meridional, en donde estamos situados desde el inicio del recorrido.

Estos materiales acabados de mencionar, forman un interesante pliegue en el lugar de la parada, a la entrada oriental al Túnel del Puerto de Cotefablo, en donde ahora estamos situados.

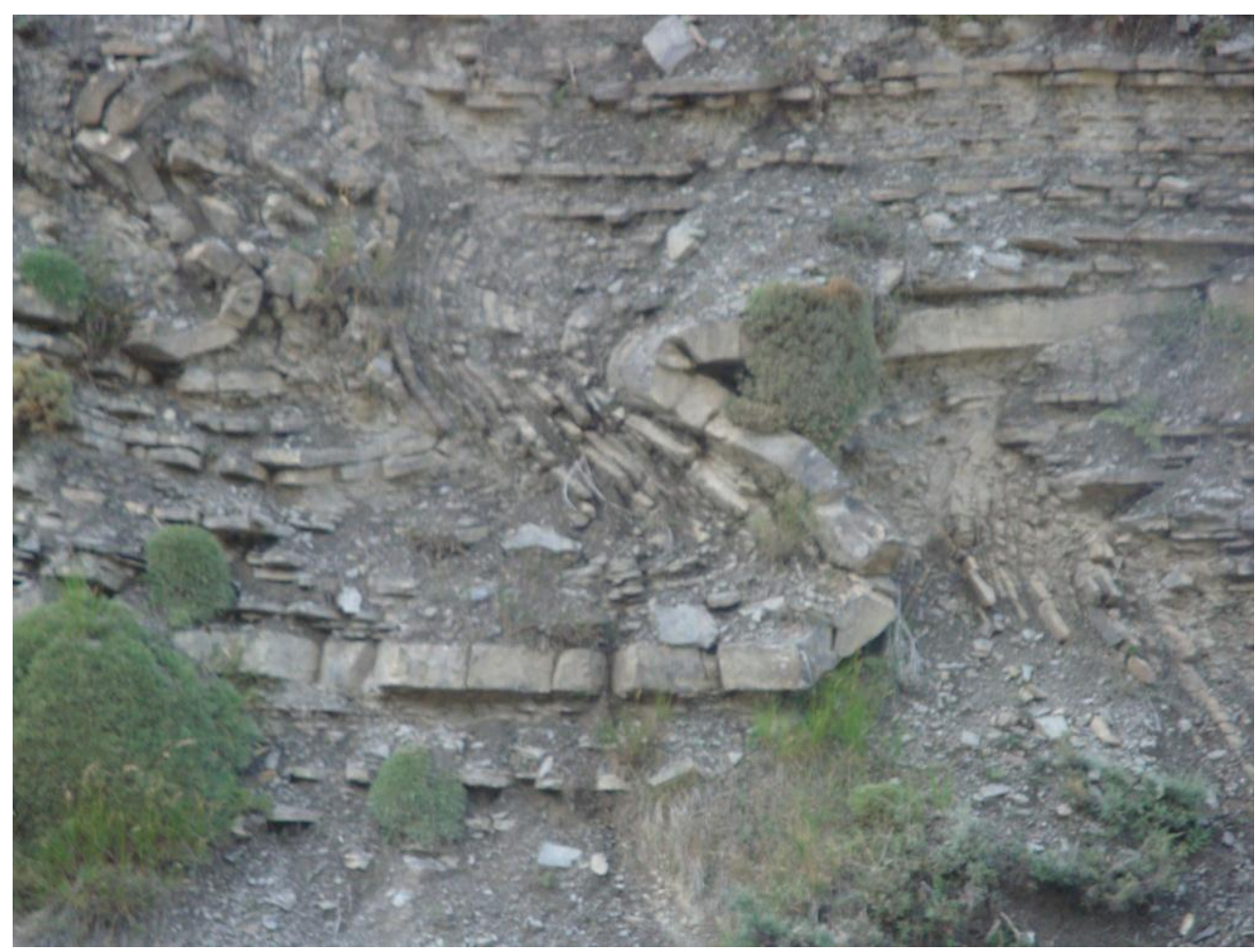

Pliegue de la entrada oriental del Túnel del Puerto de Cotefablo

PARADA 6. PARQUE NACIONAL DE ORDESA - MONTE PERDIDO. VALLE DE ORDESA, (término municipal de Torla, comarca del Sobrarbe). (Hoja 178).

Después de efectuar la parada anterior, convendrá regresar al cruce de carreteras (a $3 \mathrm{Km}$ de Broto), para continuar por la carretera que conduce a Torla. Tras llegar a este pueblo, será necesario continuar hacía el Norte, llegando hasta el conocido Puente de los Navarros. A partir de ese momento, será necesario tener una autorización para poder transitar por el Puerto de Ordesa, ya que poco después del mencionado puente, encontraremos el acceso regulado al parque. A partir de ahí, puede efectuarse un recorrido por este paraje. En cualquier caso, el recorrido desde la parada anterior hasta el Puente de los Navarros habrá sido de unos 12`5 Km, aproximadamente.

Había la posibilidad, que recomendamos, de efectuar una parada intermedia en Torla, en el Centro de Interpretación del Parque Nacional de Ordesa - Monte Perdido. Éste se halla a la entrada de la población. Desde este mismo centro de interpretación, puede verse ya una interesante panorámica del Valle de Ordesa. 


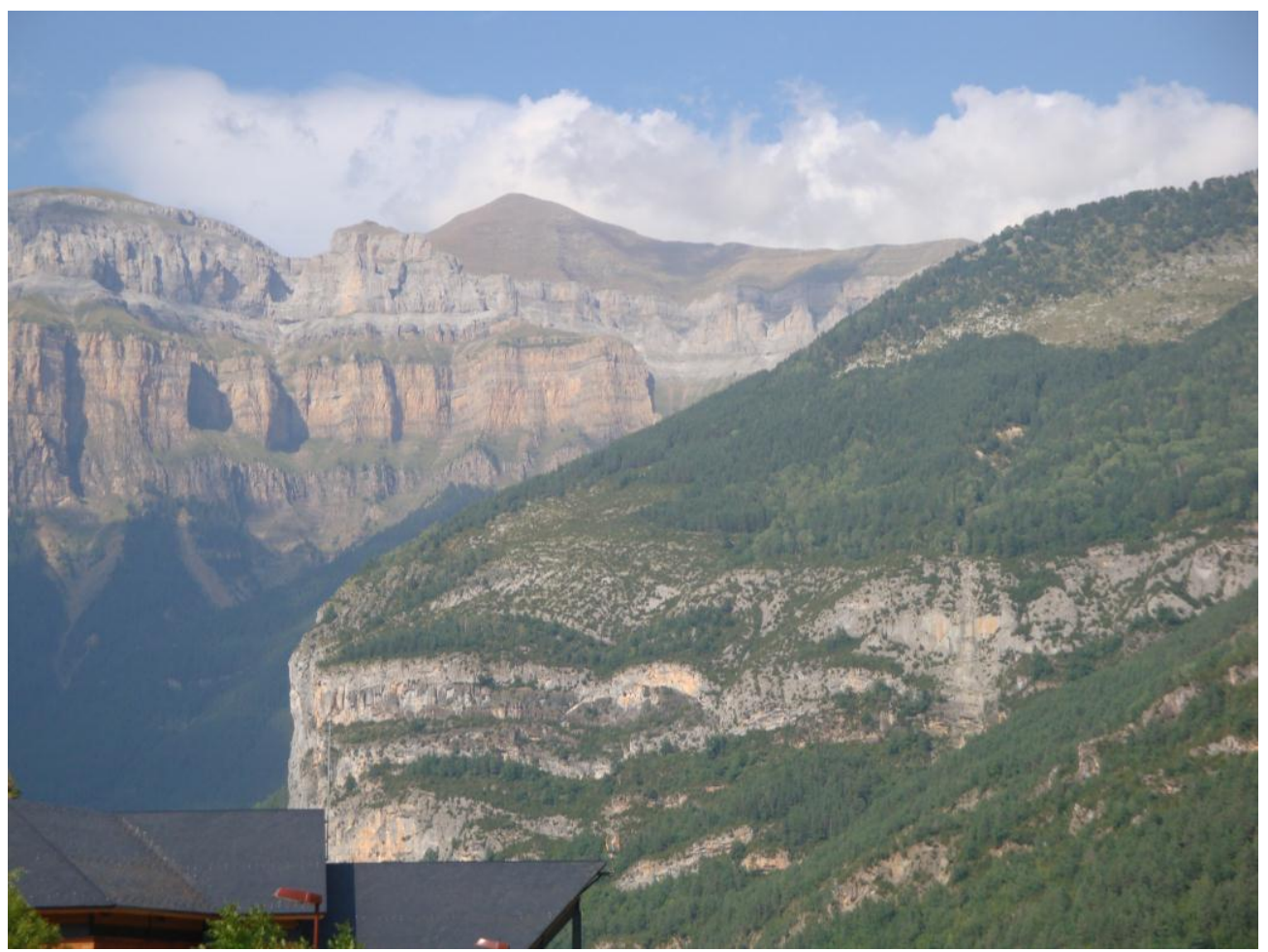

El tejado del Centro de Interpretación (Torla) con el Valle de Ordesa al fondo

En este recorrido, desde la parada anterior (en el Túnel del Puerto de Cotefablo) habremos vuelto al valle del río Ara. Luego, en el Puente de los Navarros, lo habremos dejado para continuar por el valle del río de Arazas (o río de Ordesa), tributario del Ara., en donde ahora estamos. Por otra parte, habremos encontrado afloramientos de los materiales mesozoicos y cenozoicos que afloran por esta zona. Estos materiales forman parte del Manto de Gavarnie.

Recorriendo el Parque Nacional de Ordesa - Monte Perdido, encontraremos bellos rincones de este Patrimonio Geológico. Asimismo, podremos observar como los materiales cenozoicos del Eoceno, forman las cumbres más altas.

Algunos de estos lugares, son:

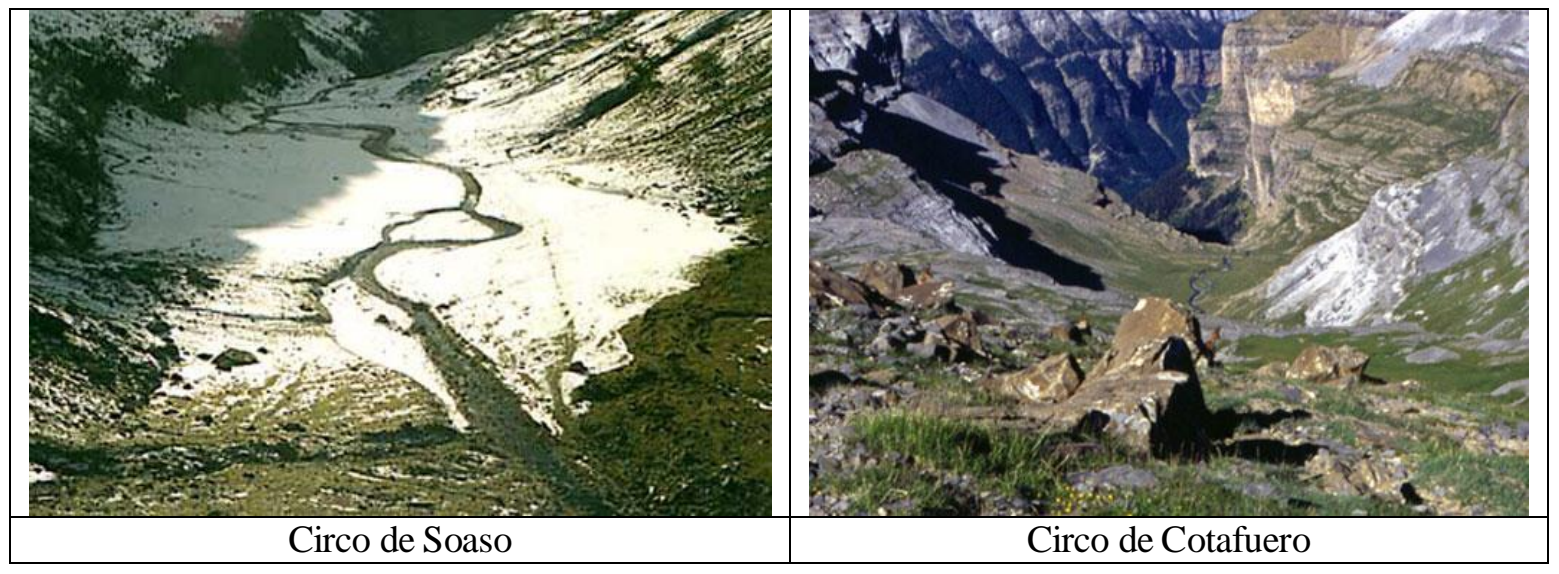

Son fotografías extraídos de la página electrónica www.ordesa.wordpress.com/2008/03/04/torla-y-algunas-fotos-del-valle-de-ordesa 
PARADA 7. VALLE DE BUJARUELO, (término municipal de Torla, comarca del Sobrarbe). (Hojas 146 y 178).

Tras realizar la parada anterior, conviene regresar al Puente de los Navarros, para seguir por el camino - carretera que remonta el río Ara por el Valle de Bujaruelo. Seguiremos así por este valle hasta el Puente de Santa Elena. A partir de ahí seguiremos a pie, durante un par de kilómetros. Así, desde el Puente de los Navarros, habremos recorrido unos $5 \mathrm{Km}$, hasta este lugar.

En este recorrido, habremos vuelto a transitar junto al río Ara. Éste forma este congosto al atravesar los materiales mesozoicos del Manto de Gavarnié. Este río nace más arriba, en el Circo de Vignemale

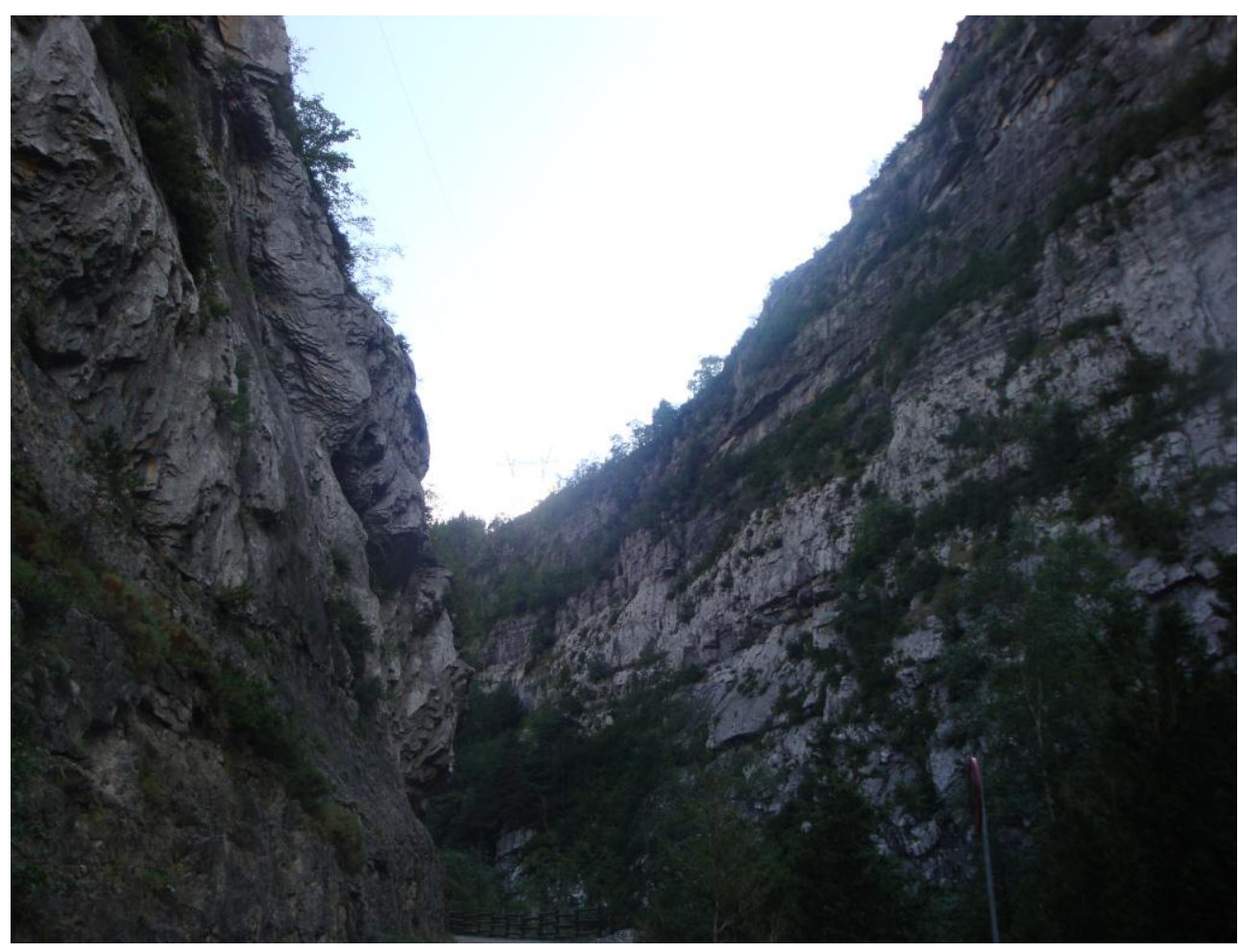

Un aspecto del Valle de Bujaruelo

EN ESTE LUGAR FINALIZA EL ITINERARIO 


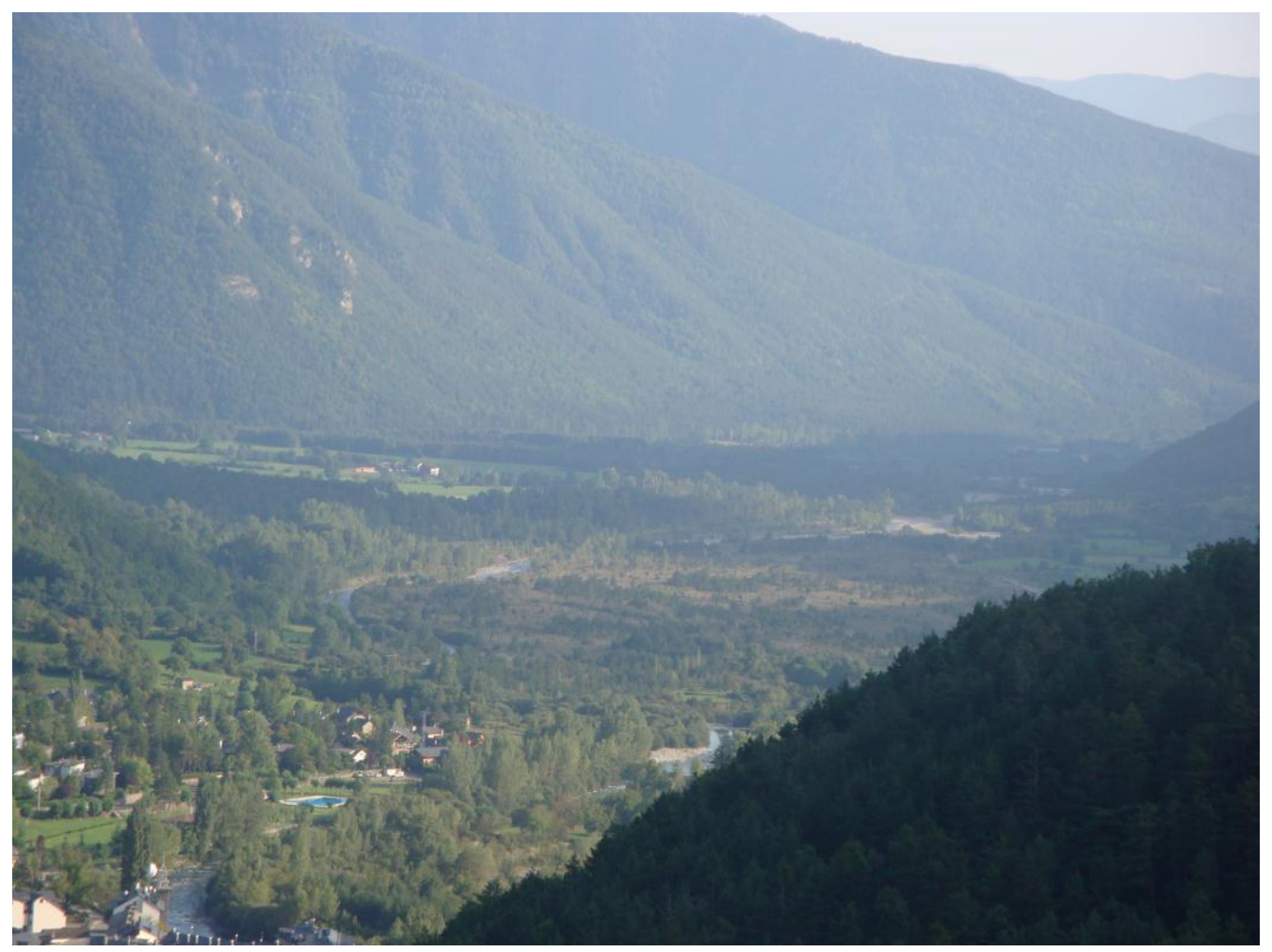

BROTO, LA LAGUNA COLMATADA DE PLNDUVIAL

\section{BIBLIOGRAFÍA}

CALVO, M. et altri (1988). - Minerales de Aragón, Colección Temas Geológicos, 207 Pág. Zaragoza

GOBIERNO DE ARAGÓN (2001).- Puntos de Interés Geológico de Aragón. Consejería de Medio Ambiente del Gobierno de Aragón. Zaragoza

IGME (1972).- Mapa Geológico de España a escala 1:200.000 (Síntesis de la cartografía existente). Hoja y Memoria na. 23 (Huesca). Inst. Geol. Min. España

IGME (1973).- Mapa Metalogenético de España a escala 1:200.000. Hoja y Memoria ${ }^{a}$. 23 (Huesca). Inst. Geol. Min. España

IGME (1975).- Mapa de Rocas Industriales de España a escala 1:200.000. Hoja y Memoria $n^{a} .23$ (Huesca). Inst. Geol. Min. España

MAESTRE, A. (1845).- Descripción geognóstica del Distrito Minero de Cataluña y Aragón. Anales de Minas, t. III. Madrid 
MATA - PERELLÓ, J.; (1987).- Introducción al conocimiento de las mineralizaciones aragonesas. Mineralogistes de Catalunya, t.III, pp. 258-265. Barcelona

MATA - PERELLÓ, J.M. (1992).- Inventario Mineralógico de la comarca del Sobrarbe. Rodeno, 13. 42 Pág. Manresa

MATA - PERELLÓ, J.M. y SANZ-BALAGUË, J. (1992).- Guía de Identificación de Minerales, adaptada fundamentalmente a la Península Ibérica. Edic. Parcir, 243 pag. Manresa

PRAMES (2005).- Sobrarbe. Colección RUTASCAL por Aragón. Prames, Gobierno de Aragón. 119 pag. Zaragoza. 